\title{
Are we all on the same page? Teacher, graduate and student perceptions of the importance of skills thought to enhance employability
}

\author{
Julie Furnell \\ University of Hull, UK \\ Graham Scott \\ University of Hull, UK
}

\section{Abstract}

Graduate employability is a key issue for Higher Education Institutions (HEls), academic faculty and of course for students themselves. It is recognised that to be employable graduates require both discipline specific skills/knowledge and more generic skills for employment. A key step to the development of the latter is an understanding of their significance on the part of those designing courses and the students who take them. Here we compare the perceived importance of key skills from the perspective of teachers, current students and recent graduates. We find that the three groups differ in the relative importance they ascribe to several key skills. Staff rated all skills as being important and saw many as being more important than did their students. With hindsight, graduates prioritized skills that were not seen as being very important by current students. As a result of our synthesising of the views of current undergraduates, employed graduates and lecturing staff, we recommend that proper signposting of the significance of key skills to students is vital.

Keywords: employability; key skills; graduate skills; biology students; bioscience students; biology faculty.

\section{Introduction}

There is a general consensus that becoming employable is an important goal for graduates (Brown et al., 2005; Saunders and Zuzel, 2010) and so it could be said that it is 
incumbent upon universities to assist students to become 'work-ready' or 'career-ready' (Raybould and Sheedy, 2005). As a result graduate employability has become an $\mathrm{HEI}$ performance indicator (Morley, 2001). However, some academics feel that the employability agenda is driven by government policy and employer pressure to the extent that their freedom to teach is challenged, and there is a an alternate view (perhaps a minority one) that students graduate as discipline specialists and it is the responsibility of employers to develop the skills of their employees (Hughes et al., 1997). Some employers believe that university courses do not prepare graduates for the work place (De la Harpe et al., 2000); others acknowledge that some skills are employer specific and best acquired in the workplace (Cranmer, 2006). We personally feel that HEls, employers and students themselves are partners in the development of a skilled workforce and that a mixed model is most appropriate. We agree that students need to be equipped with an understanding of the world of work (Mason et al., 2003), and that graduates require complimentary discipline specific skills and personal/transferable skills (Wickramasinghe and Perera, 2010).

The employability/skills agenda is not as some may think a new issue. For example, in a UK context, in 1963 the Robbins Report identified 'instruction in skills suitable to play a part in the general division of labour' as a key role for HEls (Committee on Higher Education, 1963, p.6). In 1997 the Dearing Report emphasised the importance of employability within education and of the teaching and development of transferrable skills for the workplace. Identifying a set of key skills that were 'relevant throughout life, not simply in employment' (Communication, Numeracy, IT and Learning how to learn at a higher level) (Dearing, 1997, p.133). More recently in 'Robbins Revisited', David Willetts, MP (UK Minister of State for Universities and Science), sets out the need for universities to provide opportunities for their students to graduate with a broad range of competencies beyond those traditionally seen as being core to their degree (Willets, 2013).

There is a significant body of work examining the skills required by employers and the ways in which those skills are taught to/developed by students (e.g. Hanson and Overton (2010) in the context of chemistry students; Haigh and Kilmartin (1999) in the context of geography students; Hughes et al. (1997) in the context of pharmacology students). Similarly there is a body of work examining the possibility that educators, employers and students might differ in their views (e.g. Legget et al., 2004; Leveson, 2000; Lowden et al., 2011). However, less has been written about the potentially differing perceptions of the 
importance of skills on the part of teachers, students and graduates in the Biosciences (but see Brown et al., 2005; Saunders and Zuzel, 2010).

Here we use the case study of a typical UK HEI Biosciences department to compare and synthesise the perceptions of current students, their teachers and recent employed graduates of the relative importance of key skills presumed to enhance employability. Our aim is to compare the perceptions of these three groups of people in order that we might test the hypothesis that with hindsight graduates (and perhaps tutors) see specific key skills as being more or less important than do students. To achieve our aim we collected data via a questionnaire, via semi-structured interviews (involving 15 students, nine graduates and 10 teachers), and through an analysis of the discussion strands of a Facebook group which brought together 26 current students and 35 employed recent graduates. In this short communication we present data derived from our questionnaire and inform our interpretation of those data by drawing upon our wider discussions/ interviews.

\section{Methods and quantitative analysis}

The list of key skills we have considered is presented in Table 1. It is derived from a literature review (and notably from Fraser, 2006; Hanson and Overton, 2010; and Saunders and Zuzel, 2010). All of the project participants were volunteers. Ethical approval for the work was granted by the relevant university committee and participants had the right to withdraw (and to withdraw their data) from the project at any time. All data were made anonymous prior to analysis.

\section{Table 1. Descending rank order of arithmetic mean of Likert Scores ( \pm s.d.).}

Numbers prefaced r (e.g. r1, r2 etc) indicate ranked mean level of importance for each group of respondents (undergraduates, graduates and academic teaching staff) ( $r 1$ is ranked most importance, $\mathrm{r} 2$ second etc). Skills were scored on scale of $1=$ very low, $2=$ low, $3=$ average, 4=high, $5=$ very high. Arrows show shift in rank order between each group of respondents. Skills * indicates a statistically significant difference in ranks comparing students, graduates and teachers ( ${ }^{*} p \leq 0.05$, $\left.{ }^{* *} p \leq 0.01,{ }^{* *} p \leq 0.001\right)$; Change in rank $\dagger$ indicates a statistically significant pair-wise difference in ranks ( $p \leq 0.016$; after bonferroni correction). 
Table 1. Descending rank order of arithmetic mean of Likert Scores ( \pm s.d.).

\begin{tabular}{|c|c|c|c|c|c|c|}
\hline Skills & $\begin{array}{l}\text { Student } \\
(\mathrm{N}=117) \\
\text { Mean ( } \pm \text { s.d.) }\end{array}$ & $\begin{array}{l}\text { Change in } \\
\text { rank } \\
\text { (student to } \\
\text { graduate) }\end{array}$ & $\begin{array}{l}\text { Graduate } \\
(\mathrm{N}=10) \\
\text { Mean ( } \pm \text { s.d.) }\end{array}$ & $\begin{array}{l}\text { Change in } \\
\text { rank } \\
\text { (graduate } \\
\text { to teacher) }\end{array}$ & $\begin{array}{l}\text { Teacher } \\
(\mathrm{N}=16) \\
\text { Mean (土s.d.) }\end{array}$ & $\begin{array}{l}\text { Change in rank } \\
\text { (student to } \\
\text { teacher) }\end{array}$ \\
\hline Punctuality & $4.14( \pm 0.74) r 1$ & $\downarrow$ & $3.9( \pm 1.1)$ r13.5 & $\uparrow$ & $4.31( \pm 0.60) r 11$ & $\downarrow$ \\
\hline Working as a team member & $4.09( \pm 0.79)$ r2 & $\uparrow$ & $4.5( \pm 0.70) r 1$ & $\downarrow$ & $4.38( \pm 0.61) r 7$ & $\downarrow$ \\
\hline $\begin{array}{l}\text { Ability to work without } \\
\text { supervision ** }\end{array}$ & $4.03( \pm 0.76) r 3$ & $\downarrow$ & $4.3( \pm 0.67) r 4$ & $\uparrow$ & $4.62( \pm 0.61) r 1$ & $\uparrow+$ \\
\hline Planning/organisation & $3.97( \pm 0.79) r 4$ & $\uparrow$ & $4.4( \pm 0.69)$ r2 & $\downarrow$ & $4.31( \pm 0.60) r 11$ & $\downarrow$ \\
\hline Basic numeracy $* *$ & $3.89( \pm 0.85)$ r5 & $\downarrow$ & $3.8( \pm 0.91) r 15$ & $\uparrow$ & $4.56( \pm 0.62) r 3.5$ & $\uparrow+$ \\
\hline Time management $* *$ & $3.84( \pm 0.99)$ r6 & $\uparrow$ & $4.3( \pm 0.94) r 4$ & $\downarrow$ & $4.50( \pm 0.63) r 5$ & $\uparrow+$ \\
\hline Decision making & $3.83( \pm 0.64) r 7$ & $\leftrightarrow$ & $4.1( \pm 0.99)$ r7 & $\downarrow$ & $4.06( \pm 0.68) r 14$ & $\downarrow$ \\
\hline IT Skills * & $3.79( \pm 0.88) r 8$ & $\downarrow$ & $4.0( \pm 1.05)$ r10.5 & $\uparrow$ & $4.37( \pm 0.50)$ r8.5 & $\downarrow+$ \\
\hline Oral communication $* * *$ & $3.78( \pm 0.87)$ r9 & $\uparrow$ & $4.1( \pm 0.87) r 7$ & $\uparrow$ & $4.56( \pm 0.51) r 3.5$ & $\uparrow+$ \\
\hline Written communication $* * *$ & $3.76( \pm 0.82) r 10$ & $\uparrow$ & $4.3( \pm 0.94) r 4$ & $\downarrow$ & $4.37( \pm 0.50)$ r8.5 & $\uparrow+$ \\
\hline Self-confidence & $3.74( \pm 0.89) r 11$ & $\downarrow$ & $3.6( \pm 1.17)$ r16.5 & $\uparrow$ & $3.94( \pm 0.85) r 16$ & $\downarrow$ \\
\hline Creative and innovative thinking & $3.72( \pm 0.73) r 12$ & $\uparrow$ & $4.0( \pm 0.81) r 10.5$ & $\downarrow$ & $4.13( \pm 0.71) r 13$ & $\downarrow$ \\
\hline Critical thinking/analysis $* * *$ & $3.71( \pm 0.74)$ r13.5 & $\uparrow$ & $4.0( \pm 0.81)$ r10.5 & $\uparrow$ & $4.44( \pm 0.62) r 6$ & $\uparrow+$ \\
\hline $\begin{array}{l}\text { Information retrieval/data } \\
\text { analysis } * *\end{array}$ & $3.71( \pm 0.81)$ r13.5 & $\uparrow$ & $4.0( \pm 0.81)$ r10.5 & $\downarrow$ & $4.35( \pm 0.47) r 11$ & $\uparrow+$ \\
\hline Lab techniques & $3.66( \pm 0.98)$ r15 & $\downarrow$ & $3.3( \pm 1.63)$ r18 & $\uparrow$ & $4.00( \pm 0.96) r 15$ & $\leftrightarrow$ \\
\hline Problem solving $* * *$ & $3.60( \pm 0.79) r 16$ & $\uparrow$ & $4.1( \pm 0.56) r 7$ & $\uparrow$ & $4.56( \pm 0.51)$ r3.5 & $\uparrow+$ \\
\hline Fieldwork techniques & $3.56( \pm 1.02)$ r17.5 & $\downarrow$ & $3.2( \pm 1.31)$ r19 & $\uparrow$ & $3.81( \pm 1.22)$ r17.5 & $\downarrow$ \\
\hline Scientific communication & $3.56( \pm 0.85)$ r17.5 & $\uparrow$ & $3.9( \pm 1.19)$ r13.5 & $\downarrow$ & $3.81( \pm 0.75)$ r17.5 & $\downarrow$ \\
\hline Ethical issues & $3.47( \pm 0.86) r 19$ & $\downarrow$ & $2.67( \pm 1.0)$ r21 & $\leftrightarrow$ & $3.25( \pm 0.68) r 21$ & $\downarrow$ \\
\hline Self-reflection & $3.41( \pm 0.74)$ r20 & $\leftrightarrow$ & $2.8( \pm 1.13)$ r20 & $\leftrightarrow$ & $3.38( \pm 0.88)$ r20 & $\leftrightarrow$ \\
\hline Taxonomic skills & $3.39( \pm 0.86) r 21$ & $\uparrow$ & $3.6( \pm 1.26)$ r16.5 & $\downarrow$ & $3.56( \pm 1.45)$ r19 & $\uparrow$ \\
\hline
\end{tabular}


Our questionnaire was distributed via the university's VLE to all Bioscience undergraduates at the Hull and Scarborough campuses of the University of Hull (794 students in total). A reminder email was circulated a month later and then printed questionnaires were handed out in lectures/tutorials to maximise the response rate. In total, 117 questionnaires were returned, (a 14\% response rate). Although this is a low response rate, it is adequate for a class size of over 700 (Nulty, 2008). All 35 academic teaching staff in the department were asked to complete the questionnaire (16 did so), and 10 out of 35 recent graduates we asked to complete the questionnaire did so. The questionnaire simply presented the list of skills and asked respondents to indicate the importance of each in terms of graduate employability on a 5 point Likert scale ( 5 = very important, 4 = important, 3 = neutral, 2 = low importance, 1 = very low importance).

It is clear that teachers, students and graduates do not all see the skills listed in table 1 as being similarly important. To formally test the hypothesis that students, graduates and academic staff agree/disagree in their perception of the relative importance of the skills, we used a non-parametric Kruskal-Wallis test to compare median Likert scores attributed to each skill (Table 1). Where significant test results were found, Mann Whitney tests were used to identify pair-wise differences. In the case of the latter, Bonferroni corrections were applied to minimise the likelihood of type II error, all effects are reported at a $p<0.0167$ level of significance. Between group significant differences in mean rank, the importance of nine skills were found (Kruskal Wallis $p<0.05$ ). Further statistical analysis indicated that staff ranked these nine skills as being significantly more important than did students (Table 1). There was no significant difference in rank importance of these skills between staff and graduates or between graduates and undergraduates (Table 1).

\section{Discussion of results and conclusions}

With two exceptions, all skills were rated as being on average of neutral importance or importance on the part of all respondents (self-reflection and ethical issues were rated as having low importance by graduates). The students only rated three of the skills (punctuality, working as a team member and ability to work without supervision) as being important (a mean score of $\geq 4$ ) (Table 1). In contrast, graduates and teachers both rated more of the skills as being important (12 and 15 of them respectively). It is not a surprise to us that the teachers who completed our questionnaire believed most of the skills that we 
listed to be important and made little, if any, distinction between them - after all, they have all been involved in building opportunities for students to develop these skills into their teaching practice to some extent (this was confirmed by them during their discussions with us). It is less easy to explain the differences between students and staff and between students and graduates. To attempt to do so we will draw upon the conversations we had with teachers, students and graduates (interviews and via Facebook). Our belief is that graduates come to recognise the importance of skills as they begin to apply them in an employment context. For example, staff and graduates ranked oral communication (which it was clear both they and students thought of as making presentations) as being important whilst students rated it, on average, in a neutral way (neither important nor unimportant). During our discussions (during interviews and through Facebook) it became apparent that teachers understood a high level of ability in all forms of communication to be essential if students were to do well at the job application stage and at interview, and that employers would require employees to communicate effectively in all areas of work. Graduates had come to recognise the importance of speaking with hindsight, one of them for example stated 'everyone hates presentations but they are a part of your job and interview'. Others talked about having had to speak at an interview and talked about speaking as part of effective customer service in general or as a key part of their job. During our discussions some students did see the value of presentations, but most of them added that they hated doing them. It is possible that dislike became neutrality during questionnaire completion students may find less value in those tasks they least enjoy?

On the other hand students saw punctuality (as distinct from time management) as being an important skill, but both teachers and graduates ranked it in a relatively low position compared to other skills (although the mean scores were high for all groups). This is possibly a reflection of the fact that as teachers we often impress upon students the importance of punctuality to the extent that most students perceive themselves to be lacking in this area, but that for an employed person punctuality may be a behaviour that is taken for granted and not therefore identified as a key skill. One graduate did explain that although he now took punctuality and time management for granted (in the context of being self-employed) it had been something that he found very difficult as a student.

Numeracy was recognised as being important by teachers but in discussion it was apparent that many of them felt that students had lower than expected/required abilities in this area. For example one teacher stated 'mathematical skills are essential yet weak in 
our students', another explained that this was a particular issue when poor numeracy skills meant that students were unable to identify simple flaws in their data. This is not an issue specific to our university, it is sector wide (Willets, 2013). Many HEls do not require a minimum level of maths when recruiting biosciences students and a decline in numeracy amongst biology students has been documented (Tariq, 2002). Numeracy is seen as being important by employers (Lowden et al., 2011). Our students saw numeracy as being relatively important (rank 5) but our graduates did not (rank 15). It is possible that the graduates involved in this study did not have skills in numeracy and so have found employment in areas where it is not required, but we think that this is unlikely given the jobs that we know they have.

\section{Conclusion}

We have confirmed our perception that students, teachers and employed graduates do not regard all key skills as being similarly important. Clearly the opinions of teachers are influenced by their belief that all of the components of their provision are important to all of their students. Students on the other hand value some skills more than they do others. This may be linked to their perceived ease or to the level of like/dislike they have for skills performance. Graduates appear to take some skills for granted and to focus upon the skills that they have realised they need in daily employment; through an application of hindsight graduates may revise their views. We suggest that providing opportunities for graduates to share their hindsight with current students and with teachers is likely to be a powerful tool for ongoing programme development.

\section{Acknowledgements}

This research was supported by a Departmental Teaching Enhancement Scheme awarded by the Higher Education Academy UK Centre for Bioscience. We thank the staff, students and graduates who gave their time to this project. 


\section{References}

Brown, C.A., Calvert, J., Charman, P., Newton, C., Wiles, K. and Hughes, I. (2005) 'Skills and knowledge needs among bioscience graduates - how do our courses measure up?, Bioscience Education, 6, November, pp. 1-18.

Committee on Higher Education (1963) Higher Education: Report of the Committee appointed by the Prime Minister under the chairmanship of Lord Robbins, 1961-63: 'The Robbins Report'. London: Her Majesty's Stationery Office.

Cranmer, S. (2006) 'Enhancing graduate employability: best intentions and mixed outcomes', Studies in Higher Education, 31(2), pp. 169-184.

Dearing, R. (1997) Higher education in the learning society: report of the National Committee of Inquiry into Higher Education. Norwich: HMSO.

De la Harpe, B., Radloff, A. and Wyber, J. (2000) 'Quality and generic (professional) skills', Quality in Higher Education, 6(3), pp. 231-243.

Fraser, G. (2006) 'Student skills', Centre for Bioscience, Bulletin 18 (Summer 2006), p. 3 [Online]. Available at:

http://www.bioscience.heacademy.ac.uk/ftp/newsletters/bulletin18.pdf (Accessed: 1 March 2015).

Haigh, M.J. and Kilmartin M.P. (1999) 'Student perceptions of the development of personal transferable skills', Journal of Geography in Higher Education, 23(2), pp. 195-206.

Hanson, S. and Overton, T. (2010) Skills required by new chemistry graduates and their development in degree programmes. University of Hull : Higher Education Academy UK Physical Sciences Centre.

Hughes, I., Hollingsworth, M., Jones, S.J. and Markham, T. (1997) 'Knowledge and skills needs of pharmacology graduates in first employment: how do pharmacology courses measure up?', Trends in Pharmacological Sciences, 18(4), pp. 111-116. 
Leggett, M., Kinnear, A., Boyce, M. and Bennett, I. (2004) 'Student and staff perceptions of the importance of generic skills in science', Higher Education Research and Development 23(3), pp. 295-312.

Leveson, L. (2000) 'Disparities in perceptions of generic skills: academics and employers', Industry and Higher Education, 14(3), pp. 157-164.

Lowden, K., Hall, S., Elliot, D. and Lewin, J. (2011) Employers' perceptions of the employability skills of new graduates. Edge Foundation/University of Glasgow: The SCRE Centre Research in Education.

Mason, G., Williams, G., Cranmer, S. and Guile, D. (2003) How much does higher education enhance the employability of graduates? London: Institute of Education and NIESR for HEFCE.

Morley, L. (2001) 'Producing new workers: quality, equality and employability in higher education', Quality in Higher Education, 7(2), pp. 131-138.

Nulty, D. (2008) 'The adequacy of response rates to online and paper surveys: what can be done?', Assessment and Evaluation in Higher Education, 33(3), pp. 301-314.

Raybould, J. and Sheedy, V. (2005) 'Are graduates equipped with the right skills in the employability stakes?', Industry and Commercial Training, 37(5), pp. 259-263.

Saunders, V. and Zuzel, K. (2010) 'Evaluating employability skills: employer and student perceptions', Bioscience Education, 15(2), June, pp. 1-15.

Tariq, V.N. (2002) 'A decline in numeracy skills among bioscience undergraduates', Journal of Biological Education, 36(2), pp. 76-83.

Wickramasinghe, V. and Perera, L. (2010) 'Graduates', university lecturers' and employers' perceptions towards employability skills', Education and Training, 52(3), pp. 226244. 
Willets, D. (2013) Robbins revisited. Bigger and better higher education. London: Social Market Foundation.

\section{Author details}

Julie Furnell is a research student in the Bioscience Education research group in the School of Biological, Biomedical and Environmental Sciences of the University of Hull. Her current research centers on the employability enhancing effects of learning through fieldwork. Graham Scott is Professor of Bioscience Education and Associate Dean of Learning and Teaching in the Faculty of Science and Engineering at the University of Hull. He is a Principle Fellow of the Higher Education Academy. 